\title{
Patients with renal transplant and moderate-to-severe LUTS benefit from urodynamic evaluation and early transurethral resection of the prostate
}

\author{
Marialaura Righetto ${ }^{1,2} \cdot$ Mariangela Mancini $^{1,2} \cdot$ Daniele Modonutti $^{1,2} \cdot$ Arturo Calpista $^{1,2} \cdot$ Paolo Beltrami $^{1,2}$. \\ Fabrizio Dal Moro ${ }^{1,2}$
}

Received: 26 March 2021 / Accepted: 2 August 2021 / Published online: 4 September 2021

(C) The Author(s) 2021

\begin{abstract}
Purpose To assess long-term renal function and micturition pattern of males submitted to transurethral resection of the prostate (TURP) for moderate-to-severe lower urinary tract symptoms (LUTS) after renal transplantation (RT). To investigate the role of clinical and urodynamic (UD) parameters for bladder outlet obstruction (BOO) diagnosis in these patients. Methods Retrospective data analysis of $\geq 50$ years old patients who underwent RT between 01/2005 and 12/2016. Patients with moderate-to-severe LUTS after RT who underwent a urologic evaluation and a UD study were included. TURP was performed in case of BOO diagnosis. Kidney function and micturition patterns were evaluated before, 3, 12, 24, 36, and 48 months after TURP. Predictors of BOO were assessed at univariable and multivariable logistic regression models. Statistical analysis was performed with STATA16.

Results 233 male patients $\geq 50$ years underwent RT. 71/233 (30\%) patients developed voiding LUTS. 52/71 (73\%) patients with moderate-to-severe LUTS underwent UD. TURP was performed in 36/52 (69\%) patients, with BOO diagnosis. Median (interquartile range) follow-up was 108 (75-136) months. Maximum flow at flowmetry (Qmax), International Prostate Symptom Score and post-voided residual volume improved significantly after surgery. Serum creatinine decreased and glomerular filtration rate improved significantly at follow-up, especially when TURP was performed $\leq 6$ months from RT. At the multivariable model, bladder capacity $\geq 300 \mathrm{~mL}(\mathrm{OR}=1.74$, CI $95 \% 1.03-3.15, p=0.043)$ and detrusor pressure at Qmax $(\mathrm{OR}=2.05$, CI 95\% 1.48-3.02, $p=0.035)$ were the independent predictors of BOO.

Conclusion RT patients with moderate-to-severe LUTS at risk for BOO and graft failure are better identified by UD than clinical parameters. Bladder capacity and voiding pressure are key for the early diagnosis of BOO.
\end{abstract}

Keywords Lower urinary tract symptoms · Renal transplantation · Bladder outlet obstruction · Urodynamic study $\cdot$ Graft failure $\cdot$ Voiding functional outcomes

\section{Introduction}

Advances in life expectancy have led to an increase in the number of older people with end-stage renal disease (ESRD) undergoing renal transplantation (RT). In the United States,

Mariangela Mancini

mariangela.mancini@unipd.it

Marialaura Righetto

marialaura.righetto@gmail.com

Daniele Modonutti

modonutti.daniele@yahoo.it

Arturo Calpista

arturo.calpista@aopd.padova.it

Paolo Beltrami

paolo.beltrami@unipd.it in $2016,21.3 \%$ of transplant recipients were $65-74$ years old [1]. In Europe, more than $8 \%$ of RT is performed in recipients aged $>75$ years [2]. Age-related issues become critical

Fabrizio Dal Moro

fabrizio.dalmoro@unipd.it

1 Department of Surgical, Oncological and Gastroenterological Sciences, University of Padova, Padova, Italy

2 Urological Clinic, University Hospital of Padova, Padova, Italy 
for RT success. Lower urinary tract symptoms (LUTS) due to bladder outlet obstruction (BOO) in males linearly increase with age. The incidence of moderate-to-severe voiding LUTS, classified according to the International Prostate Symptoms Score (IPSS) score [3], is about $30-40 \%$ in men aged $>50$ years $[4,5]$. This problem is underdiagnosed among RT recipients, because of oligoanuresis. LUTS can arise after diuresis restoration, with a risk to graft function. Urodynamic evaluation (UD) is required for BOO diagnosis [6]. However, UD is not routinely recommended in the preoperative workup of RT. Transurethral resection of the prostate (TURP) is the standard treatment for BOO [7] and could improve the long-term graft function in RT patients with BOO. Few studies have been published on the role of TURP in transplanted patients, with none on the relevance of combining clinical and UD parameters for a correct early diagnosis. We investigated these points in our study.

\section{Materials and methods}

\section{Population and data source}

We retrospectively analyzed data from male patients with ESRD who received an RT between 01/2005 and 12/2016 at the University Hospital of Padua, Italy. Data were collected from hospital records, outpatient visits, and hospital admissions after TURP. Before RT, patients were screened with prostate volume at trans-rectal ultrasonography, total prostate-specific antigen (PSA), and cystography (to exclude the presence of urethral stenosis). After RT, patients $\geq 50$ years with voiding LUTS who underwent urologic evaluation were considered for the study. Patients with Eastern Cooperative Oncology Group performance status (ECOG PS) $\geq 3$, New York Heart Association (NYHA) class [8] $\geq 3$, clinical or UD diagnosis of storage LUTS only, and prostate cancer patients were excluded, as well as patients with LUTS secondary to neurological disorders. Patients with moderate-tosevere LUTS, according to the IPSS score underwent UD. Antimicrobial prophylaxis was performed with oral fosfomycin trometamol ( $3 \mathrm{~g})$ the night before and after UD.

Two groups of patients were identified at UD. Group 1 included patients with moderate-to-severe LUTS and BOO diagnosis, patients with a post-voided residual volume $(\mathrm{PVR})>1 / 3$ of their bladder capacity, and patients with acute urinary retention requiring a permanent bladder catheter. All these patients were submitted to TURP. Group 2 included patients with mild-moderate LUTS without BOO at $\mathrm{UD}$, who received $\alpha 1$-blockers $\pm 5 \alpha$-reductase inhibitors. We treated separately patients without BOO at UD with voiding symptoms due to urethral stenosis or detrusor hypocontractility. TURP was performed under spinal or general anesthesia, with a bipolar $27 \mathrm{~F}$ resectoscope. Patients in both groups were evaluated at 3,12, 24, 36, and 48 months with history, IPSS, renal function, uroflowmetry (UFM), and PVR. (Fig. 1).

\section{Endpoints and outcomes}

Our primary endpoint was to evaluate renal function and graft survival at the follow-up visits after TURP. Graft survival was defined as the time from RT to the return to dialysis. Renal function was evaluated by serum creatinine $(\mathrm{sCr})$ and estimated glomerular filtration rate (eGFR) values. We then assessed the urinary functional improvement after TURP, defined as a PVR $\leq 50 \mathrm{~mL}$ with $\mathrm{a} \geq 3$-point improvement of the IPSS or a maximum flow rate (Qmax) $\geq 15 \mathrm{~mL} /$ $\min$ at UFM. Finally, we investigated the impact of the timeto-TURP on renal function.

\section{Covariates}

Demographic, clinical, and laboratory variables were collected including age, BMI (18.5-24.9; 25-29.9; $\geq 30 \mathrm{~kg} /$ $\mathrm{m}^{2}$ ), ECOG PS, NYHA class, 24-h urinary output (anuria $\leq 100 \mathrm{~mL} /$ day; oliguria $101-400 \mathrm{~mL} /$ day; preserved diuresis $>400 \mathrm{~mL}$ /day [9]), type of dialysis, stay-on-dialysis (months), prostate volume at trans-rectal ultrasonography, total PSA, ultrasound PVR, sCr and eGFR (derived using Chronic Kidney Disease Epidemiology - CKD-EPI [10]). For patients with an indwelling bladder catheter, we considered the $\mathrm{sCr}$ and eGFR levels before the catheterization. LUTS were categorized into mild (IPSS score 1-7), moderate (IPSS score 8-19), and severe (IPSS score 20-35). We considered the following UD variables: bladder capacity $(<100,100-300,>300 \mathrm{~mL}), \mathrm{Qmax}(\mathrm{mL} / \mathrm{s})$, detrusor pressure at Qmax (PdetQmax; cmH2O), PVR ( $<1 / 3$ of bladder capacity, $>1 / 3$ of bladder capacity). BOO was defined according to the Abrams-Griffiths nomogram [11].

\section{Statistical analysis}

Continuous variables were reported using mean (standard deviation; SD) or median (interquartile range; IQR) if they had a normal or non-normal distribution at the Shapiro-Wilk test, respectively. Categorical variables were reported using frequencies and percentages. The differences between baseline characteristics of continuous variables in Group 1 and 2 were examined with the 2-sample $t$ test for means and with the Wilcoxon test for medians. Differences between baseline characteristics of categorical variables in the two groups were evaluated with Fisher's exact test. We used the $\chi^{2}$ test to compare the IPSS score and PVR before and after TURP. The paired $t$ test was used to compare $\mathrm{sCr}$ levels, Qmax, and eGFR values before and after TURP. The Friedman's 


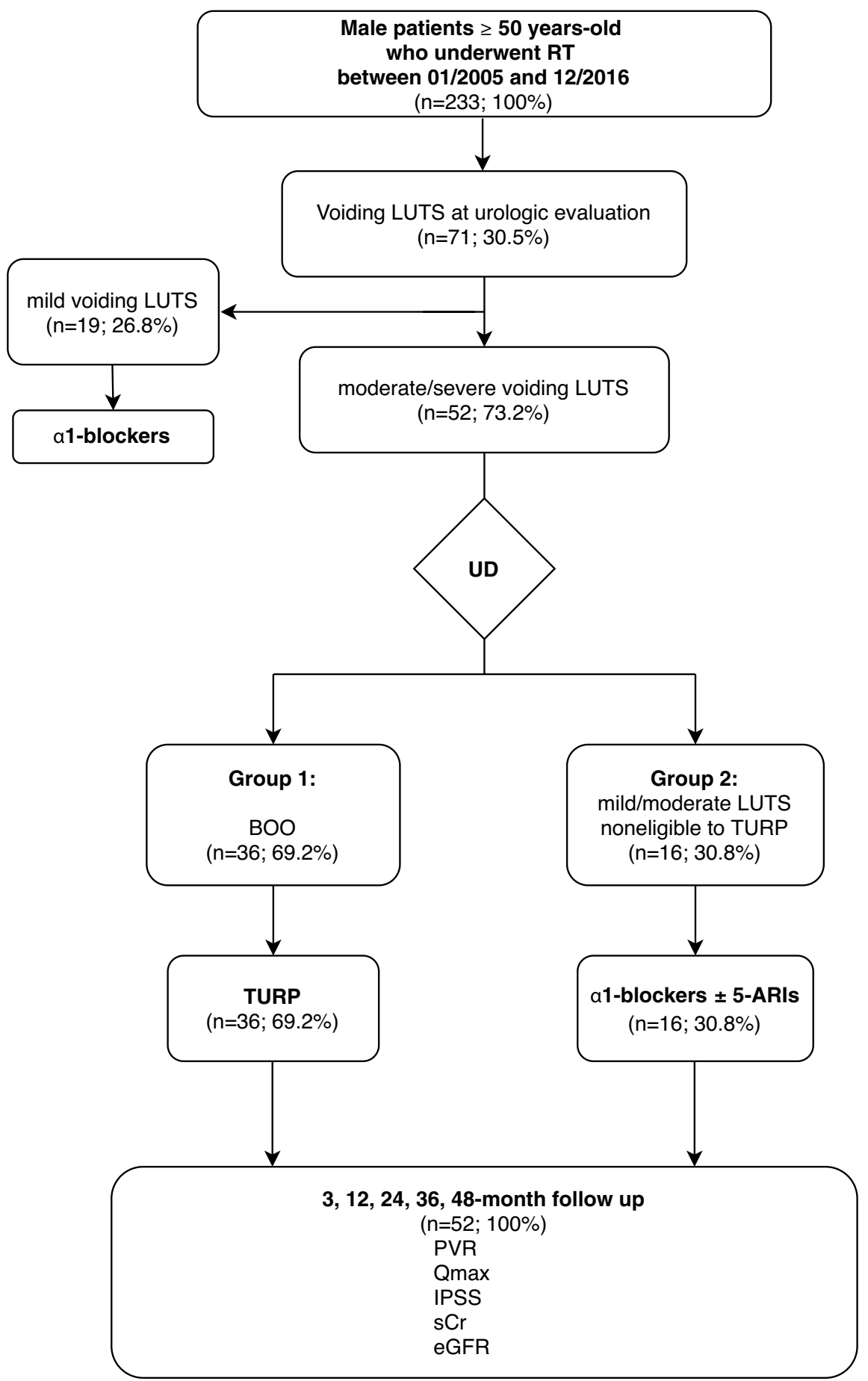

RT: renal transplantation; LUTS: lower urinary tract symptoms; UD: urodynamic study; BOO: bladder outlet obstruction; 5-ARIs: 5-alpha reductase inhibitors; PVR: post-voided residual volume; Qmax: maximum flow rate; IPSS: International Prostate Symptoms Score; sCr: serum creatinine level; eGFR: glomerula filtration rate

Fig. 1 Flow-chart of the population considered for the study design

test was used to compare sCr, Qmax, and eGFR before and after $3,12,24,36$, and 48 months. We performed a univariable logistic regression to test the prognostic significance of the covariates as predictors of BOO. Finally, variables with a significance level of $\leq 0.15$ in the univariable analysis were included in the multivariable model. Statistical analysis 
was performed with STATA ${ }^{\circledR}$ software (StataCorp, College Station, TX, USA-version 16). Comparisons were carried out at the 95\% confidence level (CI95\%); a two-sided $p$ value $<0.05$ was considered statistically significant.

\section{Results}

RT was performed in 233 male patients $\geq 50$ years old. 71 $(30.5 \%)$ underwent urologic evaluation after RT. 52/71 (73\%) were sent to UD, the other 19/71 (27\%) patients presented mild LUTS treated with medical therapy. 36/52 (69\%) patients had a BOO diagnosis at UD and underwent TURP. The median (IQR) follow-up was 108 (75-136) months.

Baseline characteristics of patients who underwent UD are shown in Table 1.

None of the patients developed symptomatic urinary tract infection (UTI) or fever after UD.

As compared to Group 2, patients in Group 1 were older, with a longer median stay-on-dialysis, a higher median prostatic volume and PVR, a lower mean Qmax at UD, a higher mean PdetQmax, and median PVR. 75\% of them had BOO at the Abrams-Griffiths nomogram, 25\% had equivocal results. The median time-to-TURP was 9 (IQR 2-12) months. Group 2 patients benefited at follow-up to drug therapy alone and did not undergo TURP.

No patient in Group 1 underwent a re-TURP during follow-up. Functional and renal outcomes of Group 1 patients are shown in Table 2. Three months after TURP, the median (IQR) IPSS and the PVR significantly decreased to 3 (1-6) and $0(0-0) \mathrm{mL}$, respectively $(p<0.001)$, while Qmax was significantly higher $(p<0.001) .53$ and $47 \%$ of the patients doubled their Qmax at 3 and 12 months, respectively, and $25 \%$ tripled it at 12 months. At the 3 -month visit, $97 \%$ of the patients had a PVR $\leq 50 \mathrm{~mL}$ and $\mathrm{a} \geq 3$-point IPSS improvement, while $89 \%$ of the patients had a PVR $\leq 50 \mathrm{~mL}$ and a $\operatorname{Qmax} \geq 15 \mathrm{~mL} / \mathrm{min}$. sCr levels were significantly lower than pre-TURP up to 36 months ( $p<0.001$ ), while the eGFR improved significantly only at the 24-month follow-up visit $(p=0.047)$. Moreover, at the first follow-up visit, despite similar baseline values, $\mathrm{sCr}$ levels were significantly lower and eGFR was significantly higher in Group 1 patients than in Group 2 ( $\mathrm{sCr} 171 \pm 93$ vs. $255 \pm 89 \mathrm{mmol} / \mathrm{L}, p<0.001$; eGFR $45 \pm 18$ vs. $33 \pm 11 \mathrm{~mL} / \mathrm{min} / 1.73 \mathrm{~m}^{2}, p=0.045$ ) These differences did not remain significant at 48 months for $\operatorname{SCr}(199 \pm 136$ vs. $175 \pm 102 \mathrm{mmol} / \mathrm{L} ; p=0.43)$, and at 36 months for eGFR ( $46 \pm 18$ vs. $44 \pm 13 \mathrm{~mL} / \mathrm{min} / 1.73 \mathrm{~m}^{2}$; $p=0.76)$.

16/36 (44\%) patients underwent TURP within 6 months from the RT (9 of these within 1 month). Unlike patients who underwent TURP later, all these patients had a PVR $>1 / 3$ of their bladder capacity, and a tendency towards a longer median (IQR) stay-on-dialysis (49 [18-76] vs. 35
[1-37] months; $p=0.057)$ and a higher median (IQR) prostatic volume (37 [26-45] vs. $24[15-31] \mathrm{cm}^{3}, p=0.053$ ). At 3 months, the IPSS score was similar in the two groups. However, there was a significant improvement in the mean (SD) $\mathrm{sCr}$ and eGFR levels only in patients who underwent TURP earlier ( $\mathrm{sCr} 154 \pm 48$ vs. $186 \pm 91 \mathrm{mmol} / \mathrm{L}, p=0.046$; eGFR $47 \pm 6$ vs. $\left.38 \pm 4 \mathrm{~mL} / \mathrm{min} / 1.73 \mathrm{~m}^{2}, p=0.041\right)$. Interestingly, patients who underwent TURP within 1 month after RT, had a higher 3-months eGFR level $(42 \pm 2 \mathrm{~mL} /$ $\min / 1.73 \mathrm{~m}^{2}$ ), albeit this trend did not reach significance, probably for the low sample size.

None of the 52 patients with moderate-to-severe LUTS underwent re-transplantation. $4 / 52$ (8\%) patients returned to hemodialysis. The graft survival after TURP was $100 \%$ at 12 months and $97 \%$ at 24 months.

Long stay-on-dialysis, PSA value, Qmax at UFM, high bladder capacity and PdetQmax predicted BOO at the univariable analysis. At the multivariable model, high bladder capacity $(\mathrm{OR}=1.74$, CI 95\% 1.03-3.15, $p=0.043)$ and PdetQmax $(\mathrm{OR}=2.05$, CI 95\% 1.48-3.02, $p=0.035)$ were the two independent predictors of BOO, while the Qmax value was not (Table 3). PSA value increased BOO risk by three folds, but this data did not reach significance, probably for the low sample size.

\section{Discussion}

ESRD incidence increases with age [12]. Improvements in surgical techniques and immunosuppressive therapies have increased the success rate of RT in older patients, who frequently have undiagnosed LUTS and could present BOO once normal micturition is restored. LUTS onset in these patients leads to high-pressure bladder storage, increased PVR, dysfunctional detrusor contraction, hydronephrosis, and graft failure [13].

A retrospective cohort study on 23.622 recipients [14] reported an incidence of $9.7 \%$ and $7.3 \%$ of BPH and TURP, respectively, 3 years after RT, without stratifying by age. More recently, a retrospective study on 131 recipients, showed a benign prostatic obstruction prevalence of 58\% between 60 and 70 years, and $71 \%$ above 70 years [15].

Reported series of TURP for BOO in RT recipients are scarce, with a short median follow-up, difficult to compare in terms of patients' characteristics, BOO definitions, and outcomes [13, 16-18]. Particularly, there is a lack of standardization in the BOO definition, as UD is not considered as a key test for patients presenting LUTS after RT.

We included in our study male patients aged $\geq 50$ years at the time of RT, who showed, similarly to other studies $[16,17,19]$, a $30 \%$ incidence of LUTS after RT. Moreover, $51 \%$ of RT recipients with LUTS underwent TURP. All recipients with moderate-to-severe LUTS were submitted 
Table 1 Baseline characteristics of the RT recipients who underwent UD $(n=52)$

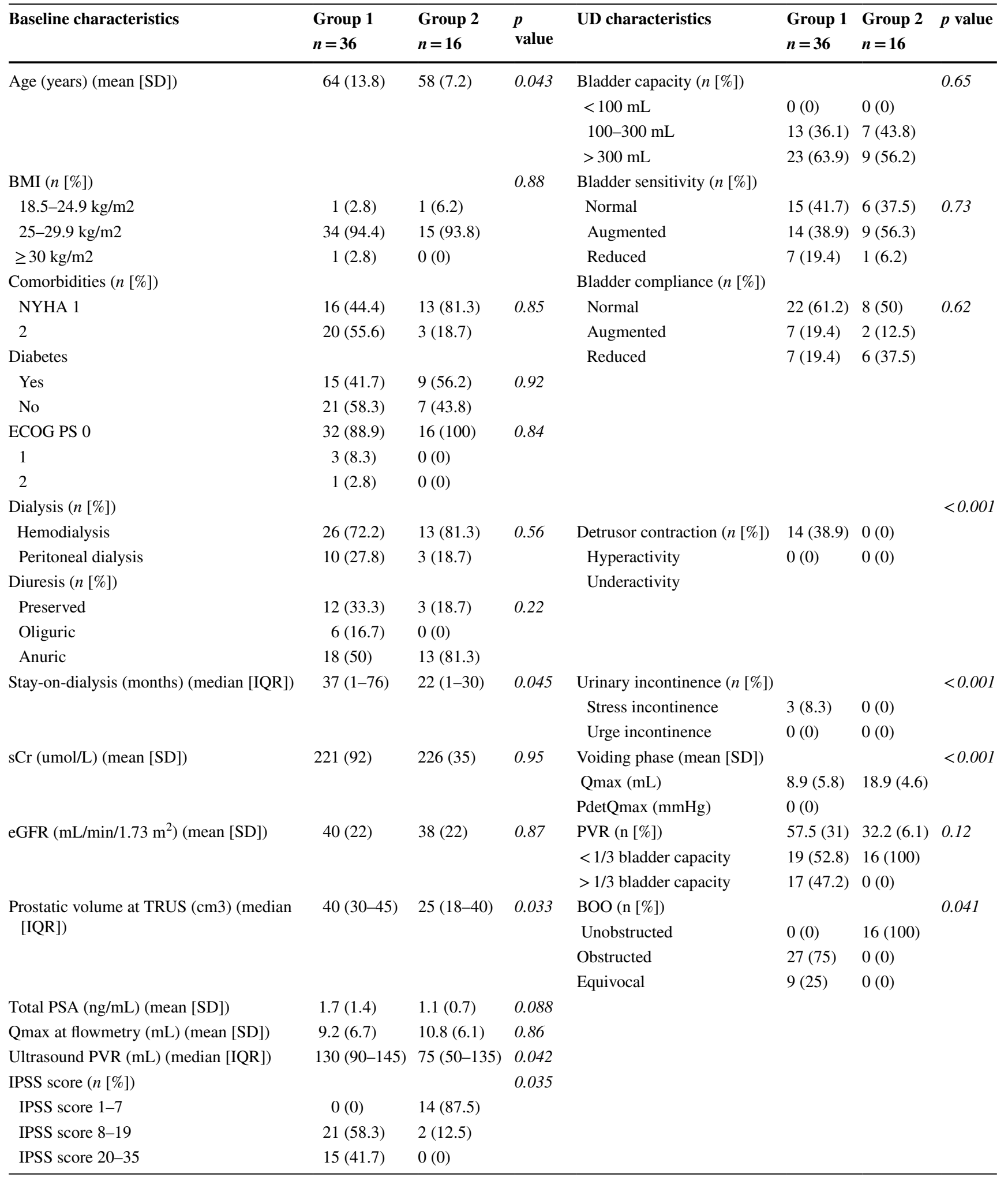

UD urodynamic study, RT renal transplantation, LUTS lower urinary tract symptoms, TURP transurethral resection of the prostate, IQR interquartile-range; SD: standard deviation, BMI body mass index, NYHA New York Heart Association functional classification, ECOG PS Eastern Cooperative Oncology Group Performance Status, TRUS trans-rectal ultrasonography, $P V R$ post-voided residual volume, IPSS International Prostate Symptoms Score, $s C r$ serum creatinine, $e G F R$ estimated glomerular filtration rate, Qmax maximun flow rate, $P d e t Q m a x$ detrusor pressure at Qmax, BOO bladder-outlet obstruction 
Table 2 Functional and renal outcomes of Group 1 patients $(n=36)$

\begin{tabular}{lllllll}
\hline & Pre-TURP & 3 months & 12 months & 24 months & 36 months & 48 months \\
\hline IPSS & $16(10-20 ; 9-23)^{\mathrm{a}}$ & $3(1-6 ; 0-6)$ & $4(0-6 ; 0-6)$ & $2(0-5 ; 0-7)$ & $3(0-4 ; 0-6)$ & $3(0-4 ; 0-5)$ \\
Median (IQR min-max) & & $p<0.001$ & $p<0.001$ & $p<0.001$ & $p<0.001$ & $p<0.001$ \\
Qmax (mL/s) & $9.6(5.5) \mathrm{a}$ & $19.2(3.2)$ & $19.9(2.7)$ & $19.8(2.7)$ & $19.5(3.5)$ & $19.1(3.3)$ \\
Mean (SD) & & $p<0.001$ & $p<0.001$ & $p<0.001$ & $p<0.001$ & $p<0.001$ \\
PVR (mL) & $130(90-145 ; 70-400) \mathrm{a}$ & $0(0-0 ; 0-75)$ & $0(0-30 ; 0-50)$ & $0(0-0 ; 0-50)$ & $0(0-0 ; 0-50)$ & $0(0-0 ; 0-50)$ \\
Median (IQR min-max) & & $p<0.001$ & $p<0.001$ & $p<0.001$ & $p<0.001$ & $p<0.001$ \\
SCr $(\mu \mathrm{mol} / \mathrm{L})$ & $258(169) \mathrm{a}$ & $171(93)$ & $154(56)$ & $158(61)$ & $157(55)$ & $199(136)$ \\
Mean (SD) & & $p<0.05$ & $p<0.05$ & $p<0.001$ & $p<0.001$ & $p=0.88$ \\
eGFR (mL/min/1.73 m $\left.{ }^{2}\right)$ & $40(22) \mathrm{a}$ & $45(18)$ & $47(20)$ & $48(20)$ & $46(18)$ & $42(21)$ \\
Mean (SD) & & $p=0.12$ & $p=0.09$ & $p=0.047$ & $p=0.09$ & $p=0.97$ \\
\hline
\end{tabular}

$R T$ renal transplantation, TURP transurethral resection of the prostate, IQR interquartile-range, $S D$ standard deviation; IPSS: International Prostate Symptoms Score, $Q \max$ maximum flow rate, $P V R$ post-voided residual volume, $s C r$ serum creatinine; eGFR: estimated glomerular filtration rate

${ }^{\mathrm{a}}$ Variable used as reference

to UD assessment, and only in the case of BOO diagnosis, a TURP was performed. In our study, UD was instrumental in sorting outpatients with BOO who required TURP, a result we could not find in previously published studies. $31 \%$ of patients who underwent UD did not show BOO and received only oral drugs. Notably, they never underwent TURP at subsequent follow-up. Moreover, UD turned out to be a safe exam, with no patient having a postprocedural UTI. This data is in accordance with recent evidence, which no longer proposes antibiotic prophylaxis even in high-risk immunosuppressed patients [20].

Performing TURP in RT recipients was clinically beneficial, in our study, according to the long-term renal and functional outcomes. Firstly, we found an improvement in sCr and eGFR levels up to 36 and 24 months from TURP, respectively. At subsequent follow-ups, sCr and eGFR levels started to get worse, probably as the result of the natural history of transplanted kidneys. Renal function improvement has been reported in previously published series $[13,16,17]$. Our study confirms this data with a higher median follow-up and highlights the fact that the improvement is higher for patients submitted to TURP than for those treated with drug therapy. An additional detail, at the 3-month visit the improvement in $\mathrm{sCr}$ and eGFR levels was higher in patients submitted to TURP soon after RT ( $\leq 6$ month), as compared to patients who underwent TURP later. Our data suggest that, in agreement with what was previously reported [17, 21], there is no reason to delay TURP in patients with moderate-tosevere LUTS and BOO after RT, and that earlier TURP (and 'very-early' $\leq 1$-month TURP) effectively improves graft function. Finally, functional outcome improved after TURP. Three months after, indeed, more than $97 \%$ of patients had a significant decrease in their IPSS score and in PVR, with an increase in Qmax, a trend stable at subsequent follow-ups.

We performed a logistic regression analysis to search for predictors of BOO specific for transplanted patients. Two clinical parameters (PSA value and Qmax at flowmetry) correlated with BOO at univariable analysis. However, at multivariable analysis, they were not independent predictors of BOO. Moreover, differently from what had previously been reported by Gratzke et al. [22], patients' age and stayon-dialysis were not predictors of BOO or TURP after RT. Therefore, no preoperative clinical parameter, evaluated with non-invasive tests, was able to accurately predict the presence of BOO. On the other hand, we did find that the onset of BOO was significantly correlated only to bladder capacity and PdetQmax, both measured at UD. Particularly, patients with a higher bladder capacity had a $70 \%$ higher risk of being 'TURPed' than those with a lower one. We could not correlate these observations with any other reported series. According to these results, UD could be offered instead of other clinical tests, as a better tool to reliably identify BOO in RT patients with moderate-to-severe LUTS.

Our study is limited by its retrospective nature, the lack of significance in some statistics can be due to the limited numbers of cases.

\section{Conclusions}

RT patients with moderate-to-severe LUTS at high-risk for BOO and, potentially, graft failure, are better identified by UD than clinical parameters. Patients without BOO at the Abrams-Griffiths nomogram can be safely treated with drug therapy alone. Urodynamic evaluation of bladder capacity and bladder voiding pressure is critical for BOO reliable 
Table 3 Univariable and multivariable logistic regression model of BOO in RT recipients with moderate-to-severe LUTS ( $n=52)$

\begin{tabular}{|c|c|c|c|}
\hline Univariable analysis & OR & $95 \% \mathrm{CI}$ & $p$ value \\
\hline Age (years) & 1.29 & $0.13-2.52$ & 0.81 \\
\hline \multicolumn{4}{|l|}{ NYHA } \\
\hline \multicolumn{4}{|l|}{$1^{\mathrm{a}}$} \\
\hline 2 & 1.33 & $0.77-1.61$ & 0.51 \\
\hline Diuresis & 0.57 & $0.48-1.21$ & 0.53 \\
\hline Preserved $^{\mathrm{a}}$ oliguric/anuric & 2.18 & $0.48-2.36$ & 0.42 \\
\hline Indwelling bladder catheter & 1.18 & $0.33-1.48$ & 0.77 \\
\hline \multicolumn{4}{|l|}{ Stay-on-dialysis (months) } \\
\hline \multicolumn{4}{|l|}{$\leq 36^{\mathrm{a}}$} \\
\hline$>36$ & 1.33 & $1.17-1.78$ & 0.038 \\
\hline PSA (ng/mL) & 2.13 & $1.33-5.24$ & 0.022 \\
\hline Qmax at flowmetry (mL/s) & 1.18 & $1.03-2.29$ & 0.036 \\
\hline Prostatic volume $\left(\mathrm{cm}^{3}\right)$ & 0.96 & $0.88-1.06$ & 0.44 \\
\hline \multicolumn{4}{|l|}{ Bladder capacity at UD (mL) } \\
\hline \multicolumn{4}{|l|}{$\leq 300^{\mathrm{a}}$} \\
\hline$>300$ & 1.54 & $1.02-2.25$ & 0.033 \\
\hline Sensibility at UD & 0.73 & $0.58-2.91$ & 0.78 \\
\hline Qmax at UD (mL/s) & 1.37 & $0.16-1.43$ & 0.57 \\
\hline PdetQmax $\left(\mathrm{cmH}_{2} \mathrm{O}\right)$ & 1.21 & $1.06-2.36$ & 0.041 \\
\hline \multicolumn{4}{|l|}{ PVR } \\
\hline \multicolumn{4}{|l|}{$<1 / 3$ bladder capacity $^{\mathrm{a}}$} \\
\hline$>1 / 3$ bladder capacity & 1.45 & $0.79-1.68$ & 0.69 \\
\hline Multivariable analysis & OR & $95 \% \mathrm{CI}$ & $p$ value \\
\hline \multicolumn{4}{|l|}{ Bladder capacity at UD (mL) } \\
\hline \multicolumn{4}{|l|}{$\leq 300^{\mathrm{a}}$} \\
\hline$>300$ & 1.74 & $1.03-3.15$ & 0.043 \\
\hline PSA (ng/mL) & 3.04 & $0.68-13.7$ & 0.16 \\
\hline Qmax at flowmetry $(\mathrm{mL} / \mathrm{s})$ & 2.51 & $0.33-4.69$ & 0.76 \\
\hline PdetQmax $\left(\mathrm{cmH}_{2} \mathrm{O}\right)$ & 2.05 & $1.48-3.02$ & 0.035 \\
\hline
\end{tabular}

$B O O$ bladder-outlet obstruction, $R T$ renal transplantation, LUTS lower urinary tract symptoms, NYHA New York Heart Association functional classification, Qmax maximun flow rate, UD urodynamic study, PdetQmax detrusor pressure at Qmax, $P V R$ post-void residual volume

${ }^{a}$ Variable used as reference

diagnosis in these patients. Furthermore, TURP performed early after RT could better improve renal function.

Author contributions Protocol/project development: MR, MM and PB; data collection or management: MM and DM; data analysis: MM and DM; manuscript writing: MM and MR; manuscript editing: all authors; revision for important intellectual contents: all authors.

Funding Open access funding provided by Università degli Studi di Padova within the CRUI-CARE Agreement. The authors have no funding to declare.

Availability of data and material The datasets generated during and/or analyzed during the current study are available from the corresponding author upon reasonable request.

\section{Declarations}

Conflict of interest The authors have no conflicts to declare.

Ethical approval All procedures in this study involving human participants were in accordance with the ethical standards of the Institutional Committee and with the 1964 Helsinki declaration and its later amendments or comparable ethical standards.

Informed consent Informed consent was obtained from all individual participants included in the study.

Open Access This article is licensed under a Creative Commons Attribution 4.0 International License, which permits use, sharing, adaptation, distribution and reproduction in any medium or format, as long as you give appropriate credit to the original author(s) and the source, 
provide a link to the Creative Commons licence, and indicate if changes were made. The images or other third party material in this article are included in the article's Creative Commons licence, unless indicated otherwise in a credit line to the material. If material is not included in the article's Creative Commons licence and your intended use is not permitted by statutory regulation or exceeds the permitted use, you will need to obtain permission directly from the copyright holder. To view a copy of this licence, visit http://creativecommons.org/licenses/by/4.0/.

\section{References}

1. United States Renal Data System (2019) USRDS annual data report: epidemiology of kidney disease in the United States. National Institute of Health, National Institute of Diabetes and Digestives and Kidney diseases, Bethesda, MD

2. Pippias M, Stel VS, Kramer A et al (2018) Access to kidney transplantation in European adult aged 75-84 years and related outcomes: an analysis of the European Renal Association-European Dialysis and Transplant Association registry. Transpl Int 31(5):540-553. https://doi.org/10.1111/tri.13125

3. Barry MJ, Fowler FJ Jr, O'Leary MP et al (1992) The American Urological Association symptom index for benign prostatic hyperplasia. The Measurement Committee of the American Urological Association. J Urol 148(5):1549-1557. https://doi.org/10.1016/ s0022-5347(17)36966-5

4. Verhamme KM, Dieleman JP, Bleumink GS et al (2002) Incidence and prevalence of lower urinary tract symptoms suggestive of benign prostatic hyperplasia in primary care-the Triumph project. Eur Urol 42(4):323-328. https://doi.org/10.1016/s03022838(02)00354-8

5. Martin SA, Haren MT, Marshall VR, Lange K, Wittert GA, Members of the Florey Adelaide Male Ageing Study (2011) Prevalence and factors associated with uncomplicated storage and voiding lower urinary tract symptoms in community-dwelling Australian men. World J Urol 29(2):179-184. https://doi.org/10.1007/ s00345-010-0605-8

6. Abrams P, Cardozo L, Fall M et al (2002) The standardisation of terminology of lower urinary tract function: report from the Standardisation Sub-committee of the International Continence Society. Neurourol Urodyn 21(2):167-178. https://doi.org/10. 1002/nau.10052

7. Oelke M, Bachmann A, Descazeaud A et al (2013) EAU Guidelines on the treatment and follow-up of non-neurogenic male lower urinary tract symptoms including benign prostatic obstruction. Eur Urol 64(1):118-140. https://doi.org/10.1016/j.eururo. 2013.03.004

8. Criteria Committee of the New York Heart Association (1973) Diseases of the heart and blood vessels. In: Harvey RM et al (eds) Nomenclature and criteria for diagnosis of diseases of the heart and great vessels, 7th edn. Little, Brown \& Co, Boston, MA, p 286

9. Bellomo R, Ronco C, Kellum JA, Mehta RL, Palevsky P (2004) Acute renal failure-definition, outcome measures, animal models, fluid therapy and information technology needs: the Second International Consensus Conference of the Acute Dialysis Quality Initiative (ADQI) Group. Crit Care 8(4):R204-R212. https://doi. org/10.1186/cc2872
10. Levey AS, Stevens LA, Schmid CH et al (2009) A new equation to estimate glomerular filtration rate. Ann Intern Med 150(9):604 612. https://doi.org/10.7326/0003-4819-150-9-200905050-00006

11. Abrams PH, Griffiths DJ (1979) The assessment of prostatic obstruction from urodynamic measurements and from residual urine. Br J Urol 51(2):129-134. https://doi.org/10.1111/j.1464410x.1979.tb02846.x

12. Hart A, Smith JM, Skeans MA et al (2020) OPTN/SRTR 2018 Annual Data Report: kidney. Am J Transplant 20(Suppl s1):20 130. https://doi.org/10.1111/ajt.15672

13. Sarier M, Tekin S, Duman I et al (2018) Results of transurethral resection of the prostate in renal transplant recipients: a single center experience. World J Urol 36(1):99-103. https://doi.org/10. 1007/s00345-017-2094-5

14. Hurst FP, Neff RT, Falta EM et al (2009) Incidence, predictors, and associated outcomes of prostatism after kidney transplantation. Clin J Am Soc Nephrol 4(2):329-336. https://doi.org/10. 2215/CJN.04370808

15. Ergesi B, Winkler Y, Kistler T, Grimm M-O, John H, Horstmann M (2016) Prevalence and management of lower urinary tract symptoms related to benign prostatic obstruction in a contemporary series of renal transplant recipients. Nephrolurol Mon 8(2):e35497. https://doi.org/10.5812/numonthly.35497

16. Volpe A, Billia M, Quaglia M et al (2013) Transurethral resection of the prostate in kidney transplant recipients: urological and renal functional outcomes at long-term follow-up. BJU Int 112(3):386393. https://doi.org/10.1111/bju.12030

17. Neri F, Di Bella C, Leone $S$ et al (2019) Lower urinary tract symptoms in kidney transplant recipients and timing of treatment with TURP: impact on renal graft survival and function. Transpl Proc 51(9):2921-2926. https://doi.org/10.1016/j.transproceed.2019.02. 072

18. Sarier M, Duman I, Kilic S et al (2018) Comparative results of transurethral incision with transurethral resection of the prostate in renal transplant recipients with benign prostate hyperplasia. Urol J 15(4):209-213. https://doi.org/10.2203/uj.v0i0.4074

19. Tsaur I, Jones J, Melamed RJ, Blaheta RA, Gossmann J, Bentas W (2009) Postoperative voiding dysfunction in older male renal transplant recipients. Transpl Proc 41(5):1615-1618. https://doi. org/10.1016/j.transproceed.2009.01.110

20. Fox C, Kim MJ, Kuo Y-H, Fromer DL (2020) Validation of the best practice policy statement on urodynamic antibiotic prophylaxis for the high-risk patient in the era of antibiotic stewardship. Neurourol Urodyn 39(8):2246-2252. https://doi.org/10.1002/nau. 24478

21. Mokos I, Kastelan Z, Basic-Jukic N, Kes P, Pasini J (2011) Transurethral incision/resection of the prostate (TUIP/TURP) in the operative treatment of repeated bladder outlet obstruction early after kidney transplantation. Acta Clin Croat 50(3):381-384

22. Gratzke C, Pahde A, Dickmann M et al (2012) Predictive factors for urinary retention following kidney transplantation in male patients. Scand J Urol Nephrol 46(1):44-47. https://doi.org/10. 3109/00365599.2011.633225

Publisher's Note Springer Nature remains neutral with regard to jurisdictional claims in published maps and institutional affiliations. 